Loading

The Journal of the Canadian Game Studies Association

LOADNG...

\title{
Buying Time: Capitalist Temporalities in Animal Crossing: Pocket Camp
}

\section{Rainforest Scully-Blaker}

Volume 12, Number 20, Fall 2019

URI: https://id.erudit.org/iderudit/1065899ar

DOI: https://doi.org/10.7202/1065899ar

See table of contents

Publisher(s)

Canadian Game Studies Association

ISSN

1923-2691 (digital)

Explore this journal

Cite this article

Scully-Blaker, R. (2019). Buying Time: Capitalist Temporalities in Animal Crossing: Pocket Camp. Loading, 12(20), 90-106.

https://doi.org/10.7202/1065899ar

\section{Article abstract}

In November 2017, Nintendo released Animal Crossing: Pocket Camp (Nintendo 2017) for iOS and Android devices. At first blush, the game is much like previous instalments in the series. The player character finds themselves as a new denizen of a rural space populated by sentient animals that all have wants and offer rewards for those that satisfy those wants. However, the conversion of Animal Crossing from console game to mobile game was not without its major changes. A free-to-play game par excellence, Pocket Camp introduces Leaf Tokens, a separate currency from bells which can be bought with real money. Leaf Tokens can be used to buy certain in-game objects but, for the most part, are used to eliminate instances of waiting in the game, which stands in direct opposition to the series' apparent valorization of slower, simpler living. Through a discussion of this translation of Animal Crossing's mechanics and values into the mobile game genre, Pocket Camp is shown to gamify the capitalist monetization of time. In the face of this reality, the paper concludes examining the role of the player as a critical actor within this system and suggests that, far from being a passive victim of the game's capitalist logics, one might engage with the game in subversive ways that articulate a virtual refusal of virtual labour and an instance of what the author has taken to calling radical slowness.
This document is protected by copyright law. Use of the services of Erudit (including reproduction) is subject to its terms and conditions, which can be viewed online.

https://apropos.erudit.org/en/users/policy-on-use/ 


\title{
Buying Time: Capitalist Temporalities in Animal Crossing: Pocket Camp
}

\author{
Rainforest Scully-Blaker \\ UC Irvine \\ rscullyb@uci.edu
}

\begin{abstract}
In November 2017, Nintendo released Animal Crossing: Pocket Camp (Nintendo, 2017) for iOS and Android devices. In many ways, the game is much like previous instalments in the series, however, the conversion from console game to mobile game was not without its changes. As a free-to-play game, Pocket Camp introduces Leaf Tickets, a new currency which can be bought with real money. Leaf Tickets can be used to buy certain in-game objects but, for the most part, are used to eliminate instances of waiting in the game, which stands in direct opposition to the series' apparent valorization of slower, simpler living. In this way, Pocket Camp is shown to gamify the capitalist monetization of time. To combat this, the paper concludes by examining the role of the player as a critical actor within this system and suggests that, far from being a passive victim of the game's capitalist logics, one might engage with the game in subversive ways that articulate a virtual refusal of virtual labour and an instance of what the author has taken to calling radical slowness.
\end{abstract}

\section{Author Keywords}

Mobile games, capital, Animal Crossing, Animal Crossing: Pocket Camp, time, labour, radical slowness

\section{Introduction: It Takes A Village...}

You are riding on a train to a place you have never been. It is your first time living away from home so you're understandably nervous, but also excited. An anthropomorphic cat (!) asks you who you are and where you're headed. You tell him because you have no other choice. He says he knows someone in town who can set you up with an affordable house. Upon your arrival, a smile comes to your face as you take in the alluringly rustic scene: from the cartoon trees that bear appetizing fruits to the very train you rode in on - a classic steam engine whose real-world forebears are all probably in museums. You are greeted by a talking raccoon. He introduces himself as Tom Nook. At this point you are used to the talking animal thing. True to the cat's words, he has property, but of course you must pay for it. You offer him your life savings, 1000 Bells. He explains that this is only a tenth of what the property is worth. Not to worry, though! He will pocket this money and you can come work for him to pay off the rest. Two minutes in and you're already in debt. Welcome to your new life, by the way.

Despite its charming, rural aesthetic, Nintendo's popular Animal Crossing series has proven vexing for game scholarship. Ian Bogost (2013) articulates this well when he identifies a tension 
that emerges between two contending operational logics in the title, which he dubs "consumption and naturalism". On the one hand, Animal Crossing's underlying aesthetic seems to celebrate the quietude of small-town life. Beyond the game's setting, certain mechanics encourage players to move slowly through the game world, both spatially and temporally. For instance, the world of Animal Crossing operates in stark contrast to most games in that it runs in real-time, which brings about moments of mandatory waiting. ${ }^{1}$

At the same time, however, the way the game measures one's progress is fundamentally capitalist. With no overarching narrative and no clear end to any game in the series, the core 'plot' of each Animal Crossing title revolves around spending Bells to develop one's property or even the town itself. Each time one's housing debt is paid in full, their house can be remodelled or expanded and so back into debt one goes. And while one's balance owed never accrues any interest, the pressure to invest substantial time and in-game currency towards the betterment of one's town and the collection of material goods (furniture, clothes, etc) can be seen to reproduce the same capitalist rhythms of labour and debt that many feel in their daily lives. In the most recent game in the series, though, this cycle has been complicated.

In November 2017, Nintendo released Animal Crossing: Pocket Camp (Nintendo, 2017) for iOS and Android devices. At first blush, the game is much like previous instalments in the series. The player character finds themselves as a new denizen of a rural space populated by sentient animals that all have wants and offer rewards for those that satisfy those wants. There are differences, too, of course. Instead of paying off a house, one pays off an RV. Instead of animals moving into your town, they loiter around your campsite. These are obvious changes. However, in order to translate Animal Crossing's core tropes and mechanics into mobile game genre conventions, there are certain changes that are more remarkable for our purposes.

A free-to-play game par excellence, Pocket Camp introduces Leaf Tickets, a separate currency from Bells which can be bought with real money. Leaf Tickets can be used to buy certain ingame objects but, for the most part, are used to eliminate instances of waiting in the game, which stands in direct opposition to the series' apparent valorization of slower, simpler living. The result is a rupture of the tension identified by Bogost. By breaking the boundary between the ingame debt of earlier titles and the real-life narratives of debt, credit cards, and potentially addictive microtransactions, any play that once existed between the naturalist, slow life ideal and the thrumming rhythm of labour and debt in Animal Crossing has been erased and only the monetization of time remains.

To trace the translation of Animal Crossing's mechanics and values into the mobile game genre, this paper begins with a discussion of the series prior to the release of Pocket Camp. The games' mechanics and aesthetics are described with a view to showing that although the operational logics of capitalism are reified in potentially troubling ways, this is somewhat undercut by the lack of any real experience of precarity on the part of the player. Next, Pocket Camp's mechanics are described with a view to showing how the series was translated to match the existing genre conventions and revenue models of free-to-play mobile games. It is shown that many of the game's new mechanics - including the presence of a new in-game currency known as Leaf Tickets - tempt the player into paying in order to avoid labour-like gameplay and tediously long wait-times. As such, Pocket Camp becomes a gamified instance of the capitalist monetization of time laid bare. To conclude, the paper briefly touches on the role of the player within this system and suggests that, far from being a passive victim of the game's capitalist logics, one might 
engage with the game in subversive ways that articulate a virtual refusal of virtual labour. Before all of this, however, it is first necessary to situate our discussion of Pocket Camp in extant scholarship.

\section{Labour, Work, and the Two Types of Slowness}

A core theoretical basis for what follows comes from Hannah Arendt's The Human Condition (1958/1998), particularly her distinction between labour and work. For Arendt, "the human condition of labour is life itself" - all that which we do to maintain our own existence and wellbeing (p.7). Labour is endless and yields no actual output other than our continued existence. "To labour [is] to be enslaved by necessity" - this is a fact that Arendt argues formed the basis for slavery in antiquity (p.83). Work, on the other hand, is all "activity which corresponds to the unnaturalness of human existence, which is not imbedded in, and whose mortality is not compensated by, the species' ever-recurring life cycle" (p.7). Put differently, work is all of that which produces objects outside of ourselves, it is how she characterizes all actions that have come to build the (human) world around us. In this paper, I distinguish not only between labour (in a broader sense) and leisure, but also between play practices that resemble labour (in an Arendtian sense) and those which resemble work, as I believe this is a way which we may most clearly see the contrast between Pocket Camp and earlier Animal Crossing titles. This distinction is paramount to what follows. For indeed, while little has been written about the more recent mobile title in the series, the earlier games have been discussed in game studies to a reasonable degree.

As noted in the introduction, one of the better-known discussions of Animal Crossing comes from Bogost in his book Persuasive Games (2007) in which he coins the term "procedural rhetoric' to describe "the practice of authoring arguments through processes", in this case the coded rules of a game (p.29). While his analysis is limited to an early entry in the series, simply titled Animal Crossing (Nintendo, 2001), many of the points he makes can still be applied to the franchise as a whole. I agree, for instance, that Animal Crossing depicts "the repetition of mundane work as a consequence of contemporary material property ideals" (p.268). While there is a lack of a clear in-game narrative, the 'story' of one's play often settles into a cycle that echoes real-life capitalist ideals.

For example, doing chores for animals earns the player furniture to display in their house. As one collects furniture, their house becomes cluttered and paying off one's housing debt and expanding one's home become necessities in order to show off the fruits of one's labour. Each house expansion costs more than the last, so this, of course, puts the player further into debt, and as the player works to pay off that debt, they inevitably acquire more items which take up space in an increasingly cluttered home. The cycle continues until the player either gets bored or can no longer expand their house.

Of course, this picture becomes less dire given that Animal Crossing is a fiction in which the player willingly participates. As Chris Crawford (1982) notes, "Games provide safe ways to experience reality" through which one can explore "the psychological experiences of conflict and danger while excluding their physical realizations" (pp.14-15). In this sense, beyond the investment of time and the initial financial investment to actually obtain the game and a console 
to play it, there is no real-world expenditure that one must make to maintain their play or indeed their enjoyment. ${ }^{2}$ One can 'play with' a particular version of going into debt, but this does not extend beyond the game itself. Bogost's work is still helpful in identifying how Animal Crossing's coded operations are injected with capitalist values that underscore even the game's slow, leisurely aesthetic. But what can be said about the relation between slowness and capital more broadly?

In this paper, I situate Animal Crossing's naturalist content within a broader social movement that strives for what is called the 'slow life'. What began in Italy as the Slow Food movement, a political and ideological force that sought to "prevent the disappearance of local food cultures and traditions [and] counteract the rise of fast life", has now spread to many other avenues of life (Slow Food, 2015). In Slow Living (2006), Wendy Parkins and Geoffrey Craig weave across disciplines to discuss the numerous ways that people deploy slowness to "promote a position counter to the dominant value-system of "the times"” (p.1). Their examples, ranging from slow food to wellness movements and even Slow Cities are carefully selected to show that "a sense of 'slow time' may interrogate the instrumental forms of social time [...] and seek to offer an alternative to speed as the only available temporality" (p.40). And while I agree to an extent, this is not to say that the slow life movement is beyond reproach. As Sharma (2014) argues, "these intellectual responses and progressive social movements that respond to the problematic pace of life risk reproducing the very social inequalities they rail against" (p.110). When imagining various ways of slowing down in life, one must necessarily ask 'for whom' this slowness gets to occur and for whom a different sort of slowness may be imposed.

Whereas 'slowness' may connote respite as in 'slowing down' or 'slow food', it can also describe inconvenience and delay, as in the case of 'slow lanes' whether on a highway or in a hypothetical internet without net neutrality. This is perhaps best captured in the phrase 'taking one's time,' a luxury reserved for those that can afford to take it whereas those who cannot more often experience slowness as having their time taken. Sharma rightly points to "multiple temporalities" that are divisible along the fault lines of class such that "experiences of time are not just the outcome of individual choices" but are variously privileged depending on what one is able to afford both financially and temporally (p.110). ${ }^{3}$ In what follows, slowness as privilege and slowness as inconvenience will be a vital distinction to make between Pocket Camp and its predecessors. As we will see, one of the chief ways that Pocket Camp deploys slowness is by filling the game with repetitive, labour-like tasks. It is by no means the first game to do so. Oftentimes, players themselves may instrumentalize their play as well.

It is interesting that two of the earliest investigations into the co-mingling of play and labour ('playbour') in the context of videogames were both set in EverQuest. Sal Humphreys (2005), conceptualizes the title as a media object and virtual world where "the line between production and consumption of the text have become blurred" (p.37). Given that EverQuest is one of the first Massively Multiplayer Online Role-Playing Games (MMORPG), it comes as little surprise to a contemporary reader when Humphreys writes that "the trajectory of gameplay is thus contingent upon the particular dynamics and action generated by [...] players" (p.40). Members of the play community itself, he argues, have become the authors of the game's narrative and so play itself has become 'productive'. And while there is certainly room to examine the 'work' of world building here, Humphreys himself does not do so. 
The tension of play practices resembling labour practices in EverQuest is taken up more explicitly by T.L. Taylor in Play Between Worlds (2006). In it she describes, among other things, EverQuest community members who take part in "instrumental play", or a manner of interacting with a game that is characterized as "efficient, almost quantitative" in its approach (p.74). Instrumental players approach a game as a system to master rather than as a way to relax or pass the time such that "at times it appears as if they are speaking of work" when describing their play (p.88). She relates this to Roger Caillois' (1958) notion of the "contamination" of play that occurs when it is coloured by professionalization or other external forces (p.45). And while her focus is on players, who may opt to play instrumentally, ours is on games, which can reify labour by design.

Shira Chess' (2017) recent book, Ready Player Two: Women Gamers and Designed Identity takes up and problematizes this very issue in compelling ways. In it, she works to "discuss the larger shifts within and around the video game industry that are both inviting in women audiences yet keeping them at bay" by examining the tension that exists in the representations of gendered leisure (p.6). Being "time positive" - that is, flexible in how and when a game can be played - "is a core concept at the root of both the lived realities as well as the perceived lives of women players" (p.60). Play, here, is therefore framed as both operating in opposition to work (as not-work) and in service to it (as productive play that is squeezed between periods of work). In framing play this way, Chess recalls Giorgio Agamben's (2011) claim that "we are no longer able to reach menuchah," or a state of positive "inoperativity" (p.106). As Chess and Taylor have shown, leisure can no longer be expressed in western culture without reference to labour (i.e. as 'not-labour').

This is one of the more nefarious incarnations of the problem of 'playbour'. Given that figure of the 'woman gamer' here is often working full time both "in offices and in household management", games that are geared towards this demographic are often "about allotting specific moments for productive play" (Chess, 2017, p.61). Play, here, is implied to be wasteful if it is not done for the sake of personal cultivation that goes beyond the game itself. ${ }^{5}$ Given the role of play as a flexible time-filler, many of the games Chess examines are, like Animal Crossing: Pocket Camp, mobile games that one can play 'on-the-go'. Games of this sort have accumulated a set of genre conventions which require a particular vocabulary that will be central to the discussion to come.

The most important divergence of mobile game design from pre-existing practices is the crafting of value. As Mia Consalvo and Chris Paul (2015) note, "By virtue of its long lifespan and its primary use by notable developers, the single fee for a game as product has been normalized over time and is a key marker of what is expected from a regular, 'real' game" (p. 2). Though the standard retail price for videogames has changed over time, it is only with the onset of online gaming that we have begun to see pricing models that account for more than one instance of payment. Consider, for instance, Downloadable Content (DLC) - one may purchase a game and then, several months later, DLC may be released that adds more to the experience. Sometimes such content is offered free of charge but this is not often the case. Still, it is rare that such content is a mandatory purchase. Mobile games, on the other hand, exist in an entirely different ecosystem. ${ }^{6}$ 
"Known as free-to-play, freemium, or occasionally as the derogatory pay-to win" this pricing model shifts the cost of a game from "a relatively larger upfront sum into a series of smaller, generally optional, yet advantageous purchases" (Consalvo \& Paul, 2015). These expenditures, often called microtransactions, are notorious for their low cost and ease of execution. It is not uncommon, for instance, to hear accounts of children who manage to accrue bills for thousands of dollars from the App Store or Google Play Store because these purchases are so simple or tempting. For although spending money is indeed optional, game developers have honed a variety of manipulative techniques to earn a profit.

There are too many approaches to list here, but they can range from simple advertising revenue to a casino model with a few "whales' "spending a substantial amount of money on the game" with the ideal goal being that all players are inclined "to spend a modest amount on playing the game" (Consalvo \& Paul, 2015). And while Pocket Camp's approach is not too different from other well-known 'freemium' games, the broader context of the Animal Crossing series complicates these profit-making mechanisms in interesting ways. Before speaking more about Pocket Camp's pricing model, then, a wider framing of Animal Crossing through its understanding of time, leisure, and labour is necessary.

\section{Animal Crossing and the Playbour of Maintenance}

Before delving into Pocket Camp proper, some background on the Animal Crossing series is warranted since the design of these games is relatively unique. For instance, whereas it has been noted elsewhere ${ }^{7}$ that many games are designed in a way that values speed as a force of advancement and domination, games in the Animal Crossing series are some of the few examples which seem to do the opposite. Beyond Bogost's naturalism, many of the game's mechanics, such as befriending your animal neighbours or creeping up on butterflies to catch and add to the town's museum, also suggest that the player take their time. One such moment that has had a lasting impact on my work can be found in Animal Crossing: New Leaf (Nintendo, 2012).

In New Leaf, on one end of the town's Main Street (a place largely reserved for small businesses), there is a bench placed at the edge of a cliff that overlooks the ocean (see Figure 1). Though there is no prompt to do so, by moving towards the seat a player can, if they wish, rest their avatar on the bench and wait for nothing in particular. There is no in-game stress metre to deplete and the player is certainly not offered any material gain for their action. After a few seconds, the camera may pan up slightly to show off the sky and a street lamp may ignite as the in-game clock detects the arrival of the evening, but the bench serves no in-game purpose other than a place to sit and listen to the lapping waves. Though I undeniably approach this gameplay segment from a place of nostalgia, this is a remarkable gameplay mechanic. Players are offered a moment to perform leisure for leisure's sake within the virtual world of a videogame which is itself ostensibly a leisure object. ${ }^{8}$ 




Figure 1-A moment that, while unassuming, was unlike any other that I had experienced in a videogame

As someone whose research has historically centered on games and speed, I have also been struck by the fact that Animal Crossing is one of the few games that punishes the player for running rather than walking without stealth being a core gameplay mechanic. In most games, one sneaks to avoid detection whereas in Animal Crossing one walks to avoid trampling flowers or scaring off fish and insects that can be caught and either sold or donated to the museum. Whether the player wishes to wear the hat of a capitalist, conservationist, or a landscaper, they would do well to walk from place to place. It is not as though running is ever made necessary either.

As stated in the introduction, the game runs in real-time. Any events that are time sensitive (the hours of operation of the town's businesses, the hours that your animal neighbours wake up or go to bed, etc.) depend on our everyday notion of time rather than the contraction of days into minutes that is characteristic of many other games. Since the game world is relatively constrained (it is a 'small' town, after all), the player can travel from one end of town to the other in under five in-game minutes. In other words, one's gameplay is never a race against the clock. This is not to say that there is no 'playing' with time in the way that Chess (2017) discusses.

Although the passing of the hours in Animal Crossing is more relaxed than in most games, the decision to tie the in-game clock to the actual rate at which we measure time is deployed in a manipulative way. Although a player's individual play session may be as slow-paced as they wish, one of the core features of Animal Crossing is that it simulates the passage of time even when the player is not playing. Animals may even decide to move out of the player's village while they are away. The only way to prevent this in most cases is through playing the game regularly and happening to speak to a villager that is planning to move, potentially talking them out of it. On the one hand, this gives the animal villagers an immersive amount of depth since they will recall what the player said to them earlier in the week or may even comment that it has been a certain number of days since the player spoke to them last. But claiming that the player's town keeps existing even when they are not around weakens the distinction between one's play time and other times.

If the player cannot play for a week, for instance, they may miss certain random events such as a special merchant visiting the town. Weeds will begin to grow as well, and the player may enter their home after a long break from playing to find that one or more cockroaches are scuttling around. The town itself begins to lose its lustre if the player does not maintain it. And while the game's sequels have softened the punishment for not playing, animal villagers still essentially 
guilt the player for not playing for long stretches of time (see Figure 2). In an interesting reversal of the idea that one can never quite 'turn off' from their working life, in Animal Crossing, one is altogether incapable of 'turning off' the game's monitoring of their play.

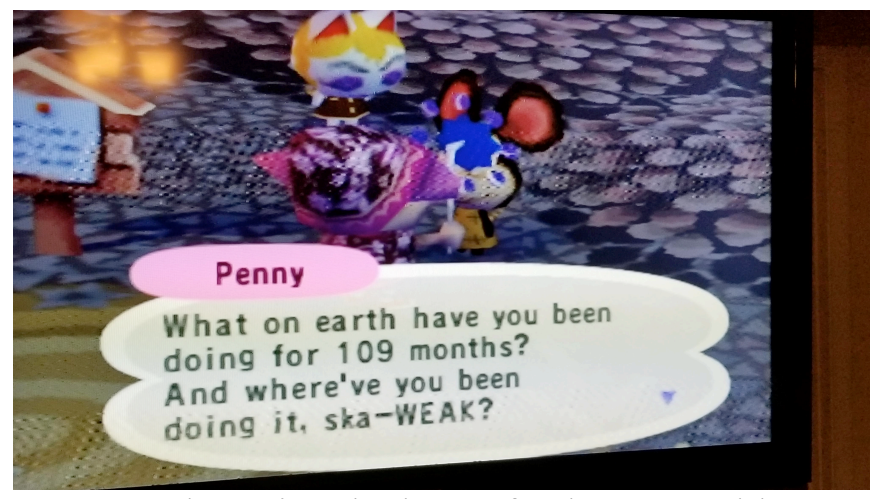

Figure 2 - A player is asked a perfectly reasonable question.

It strikes me that one's play here is subsumed into labour, articulated by Arendt (1958/1998) as "the maintenance of life" - or, in this case, a virtual world and many virtual lives (p.28). For indeed, although it would seem that much of Animal Crossing's core gameplay is geared towards 'making' one's world as they see fit (in later games one becomes mayor of the town and can even choose from a limited selection of ordinances to put into law), most if not all of the in-game activities available to the player are less about enacting one's vision, but rather maintaining it.

Once a save file is created, the town as infrastructure will exist with or without the player's input - while the player can alter the town through the expenditure of time and Bells, I would argue that none of these affordances take the form of 'work' in the sense of building "a common world" (p.28). While it may be that the "effort and pain" that Arendt ascribes to labour cannot fully apply to a virtual world, what is significant here is that the player is made to feel responsible for maintaining their town and its inhabitants (p.48). This constant feeling of obligation towards maintenance recalls Bandai's infamous Tamagotch $i^{9}$ or indeed a wide variety of freemium mobile games, Pocket Camp included.

Before the 2017 release of Pocket Camp, then, we can see that there already existed a tension between the Animal Crossing as a leisurely pastime and the actual gameplay's call for a constant engagement on the part of the player. Whereas most games progress at a rate dictated by the player - one might play a game for hours one day and then not again for several days, for instance - Animal Crossing strongly suggests that a player avoid such arrhythmia. Features such as the growth of weeds or the selection of items in the local shop that rotates daily encourage the player to engage regularly and in short, almost picnoleptic ${ }^{10}$, episodes. When read this way, there emerge a number of family resemblances between the Animal Crossing series and many mobile games that were released subsequently. However, there is one key difference.

As noted above, beyond the requisite financial and temporal capital to purchase and play Animal Crossing, the game itself does not tread into issues of privilege or precarity. Any impulse that the player feels to maintain their town, while a symptom of the game's more manipulative features, does not result in any real-world subjugation to the operational logics of capitalism. If anything, 
the 'procedural rhetoric' of Animal Crossing's capitalism is so overt that I would argue it operates against the player ever becoming some sort of cultural dupe. ${ }^{11}$

And while Animal Crossing did interface with other Nintendo hardware as a way to expand the range of possible interactions within the game world, these accessories were not necessary to experience the vast majority of what the game had to offer. Bogost (2007) supports this when he notes that these peripherals, and indeed the game as a whole, offer even young players an opportunity to "experiment" with their "commercial attitudes" (p.275). Put simply, the selfcontained nature of Animal Crossing's virtual world allows players to experience acquisition and debt without the threat of financial precarity. With the translation of Animal Crossing's setting and mechanics to a freemium model of game design and revenue, however, this is no longer the case.

\section{Pocket Camp and the Deployment of Slowness}

At the time of writing, Animal Crossing: Pocket Camp has been available on mobile devices for nearly one year and while various features have gradually been implemented during this period, the game's premise and mechanics have remained the same. Upon starting the game, the player character emerges from an RV parked in a quiet and sparsely decorated campsite. Within moments, the player is mistaken for the campsite's manager in a manner that recalls how the player becomes mayor in Animal Crossing: New Leaf. Any attempt to dissuade the welcoming party that the player is simply here for a vacation is ignored and the basic gameplay tutorial begins. While certain mechanics, like collecting and arranging furniture, are familiar to fans of the series, there are many new rules as well.

Since the player is now managing a campsite instead of a town, the process through which animal campers (no longer villagers) come to the player's space is different. The player must first go out and meet these animals and 'level up' their friendship to a point where the animal camper is interested in coming to visit. Friendship points can be earned by collecting particular combinations of fruit, fish, and insects and giving them to the animals as gifts. In return, the player receives friendship points and crafting materials. If one wants a particular piece of furniture, it is usually up to them to collect enough materials to make the furniture themselves. The construction of furniture holds new significance because, even if an animal camper is at a level that they want to visit the player's campsite, they will refuse to do so unless a specific set of furniture is present (see Figure 3). ${ }^{12}$

Populating one's campsite with visitors is one of the major goals of the game, and happy animal campers reward the player with Bells and crafting materials for letting them 'hang out'. All interactions with the animal campers that boost friendship points also boost the player's own personal experience points and the player is rewarded each time they level up with more materials, more furniture blueprints, and more animal campers to pursue. What remains of traditional Animal Crossing gameplay is contained in one's RV, which here serves the role of the player's 'house' in that it can hold furniture (that does not count towards an animal's willingness to visit you) and it can be expanded for Bells. 


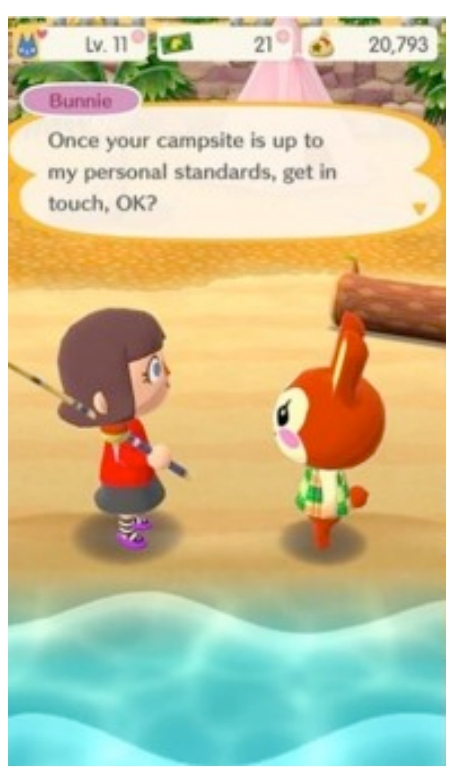

Figure 3 - Friendship is given a materialistic twist in Pocket Camp

This, then, is a basic summary of the gameplay in Pocket Camp: players collect goods to give to animals for money, materials, and friendship points and these resources are converted into furniture which satisfies the player's aesthetic sensibilities while also leading to the chance for more resources. This cycle continues until the player either gets bored or there are no more animals to befriend, although Nintendo is patching the game constantly to add new animals as well as special time-sensitive events that the player can partake in. Playing regularly is also incentivized through small rewards for simply logging in each day, so player retention is clearly a design goal. With the core gameplay explained, we are now ready to move on to the matter of time in the game.

Everything in Pocket Camp functions in a segmented version of real-time. There are several environments other than one's campsite that the player can visit to speak with animal campers or gather resources, and the amount of time that an animal will stay in one place is based on a fourhour timer. As such, these four-hour cycles dictate the pace of much of one's gameplay. After that time has elapsed, the game will randomly disperse different animals in these environments. This creates a pressure similar to that of earlier games in the series to log in regularly and go through the available set of routine tasks. Instead of doing so say, once a day, in Pocket Camp one is only playing efficiently if they return every four hours when the world 'resets'.

Within the four-hour period, the animal campers will only have three requests each for the player unless the player uses an item to 'refresh' their desire for more butterflies or apples. This is not necessarily as advantageous as it may initially seem since fruit trees will only re-grow their fruit after six hours unless, again, the player uses an item to 'restock' the tree. Fish and insects are always available but become far less common over time unless the player takes a break. However, there are special tools to catch multiple bugs or fish at the same time independently of how many the player has already gathered. Entropy of resources is an overwhelming force that leads to much forced waiting for the next four-hour cycle unless the player has these special items. But this is not all that one must wait for. 
Whereas in other Animal Crossing titles, the player simply purchases furniture from local shops, here they must commission pieces from the local crafter. And while most of the furniture in one's early-game catalogue (including the pieces that attract the first few animals one meets) take mere minutes to construct, as one plays for longer and levels up, the wait steadily gets longer. The longest I have personally encountered is a 72-hour wait. This is exacerbated by the fact that the player can only initially construct one piece of furniture at a time. If an object takes three days to build, then nothing else can be made in that time unless the player acquires more build slots. But, of course, while the player waits, they still have the option to log in and take care of their chores every four hours.

Unlike earlier Animal Crossing games where the slowness of play was an aesthetic value that was reflected in optional mechanics such as choosing not to run from place to place (where slowness was a measure of leisurely pleasure), in Pocket Camp the deceleration of one's gameplay is a hindrance that is forced upon the player as they progress through the game. But, like any true freemium game, Pocket Camp offers the player a way to circumvent this deployment of slowness as an obstacle to fun.

Enter Leaf Tickets, a new currency that is distinct from Bells both in what one buys with it and in how one earns them. Put simply, the primary purpose of Leaf Tickets is to eliminate any of the above wait times. The chief way of acquiring Leaf Tickets is by purchasing them with real money via credit card (see Figure 4). If the apple trees simply need to bear fruit this second, you can pay. If you want to skip right to that furniture being built, you can pay. Even if you lack the requisite materials to build a particular object, the crafter can spin Leaf Tickets into wool, wood, and metal. If one is willing to pay, most of the game's repetitive chores (and with them, most of the game's mechanics) become unnecessary.

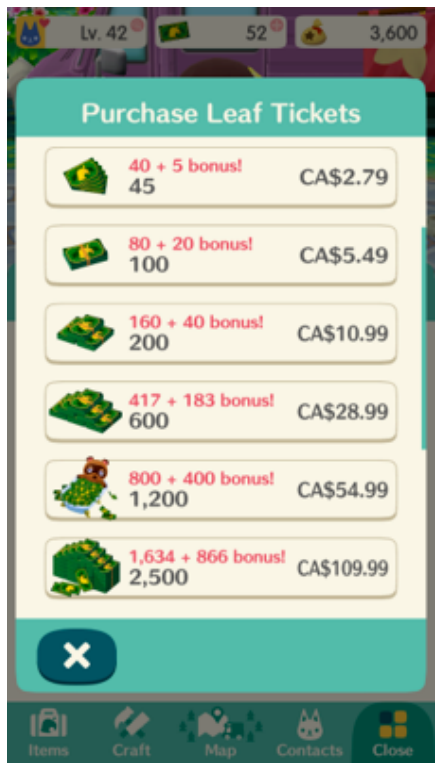

Figure 4 - The going exchange rate for Canadian Dollars to Leaf Tickets

Although downloading and interacting with the game is free, the way Pocket Camp is made incentivizes these in-app purchases by gradually making the gameplay more sluggish through increasing the amount of time and materials necessary to craft new furniture. The relation 
between time and value has been reversed here - instead of paying to play Animal Crossing as a way to relax as one once did, the Pocket Camp user now pays in order to eliminate particular segments of play-time in all their drudgery.

While it may seem as though players are paying solely to speed up their gameplay, I argue that they are paying to eliminate the tedious vacuum that exists between those moments in the game that are pleasurable for their slowness. Imagine the gameplay of Pocket Camp without waiting: one has a catalogue of all the available furniture in the game world and they can build any of it at the push of a button. ${ }^{13}$ One can then immediately add it to their campsite and make manifest their interior (well, exterior) design vision. There is no delayed gratification here. All animals will become fast friends with the player and the campsite becomes a space of possibility that is limited only by the in-game rules and assets and one's own creativity. One effectively transforms the game from one of mundane, repetitive chores and long wait times into a world that can be built and decorated according to the player's wishes.

This contrast between the standard gameplay to this 'pay-to-God' model recalls Sharma's notion of multiple temporalities that are divided along class lines. While Pocket Camp is free, for those who are unwilling or unable to pay real money, the only way to progress through the game and build the campsite of one's dreams is to labour (in an Arendtian sense) through the segments of play that involve stockpiling resources and expanding one's furniture catalogue until one arrives at the comparatively brief moments of what might be readable as the playful 'work' (or workful play), of world-building, and of enacting one's will on the game environment. It is in these moments that the game's naturalist setting and the zen-like practice of adjusting the layout of one's camp that a leisurely slowness is experienced.

The only major difference between paying Nintendo to not wait 72 hours for a particularly nice table in Pocket Camp and, say, paying Amazon to ship a package in one day is that within the virtual space of Pocket Camp, the time and labour are not outsourced to someone else, it is simply removed altogether. In a sense, this may be a rather utopic idea, but it is difficult to ignore how many microtransactions must necessarily go into such a play practice (or indeed the exploitative labour practices that are characteristic of 'crunch' in game development).

In earlier Animal Crossing games, any financial expenditures on the part of the player were done in Bells. In Pocket Camp, players can choose for their spending to be directly tied to their actual financial standing. It is incredibly simple to complete microtransactions in-game (as few as one or two finger taps) such that one may even forget how many have been made or how much money has been charged to their credit card. In this way, the risk-free encounter the player has with virtual debt in earlier titles has the potential to bleed into the real world where financial precarity is often a fact of life. From what has been said here of Pocket Camp's mechanics and what others have noted about the addictive qualities of mobile games that echo research on gambling addiction ${ }^{14}$, it is wholly conceivable that someone might be tempted to make in-app purchases that go beyond their financial means - credit cards exist for the sake of credit card debt.

Pocket Camp, then, has carried its operational logics of labour and consumerism into the realm freemium game design (see Figure 5). While players require no capital up-front, the game uses 
labour-like chores and a steadily-increasing ratio between wait-time and play-time to make the game actively less enjoyable to play unless one spends money. It is interesting that this disrupts even the already-problematic idea that mobile games are meant to be played in the tiny gaps we have between our regularly-scheduled periods of work. A player cannot pick up Pocket Camp where they left off like they might a game of Solitaire. Instead, the game asks that players schedule their lives around it unless one is able to pay for the privilege of escaping those parts of the game that are most labour-like.

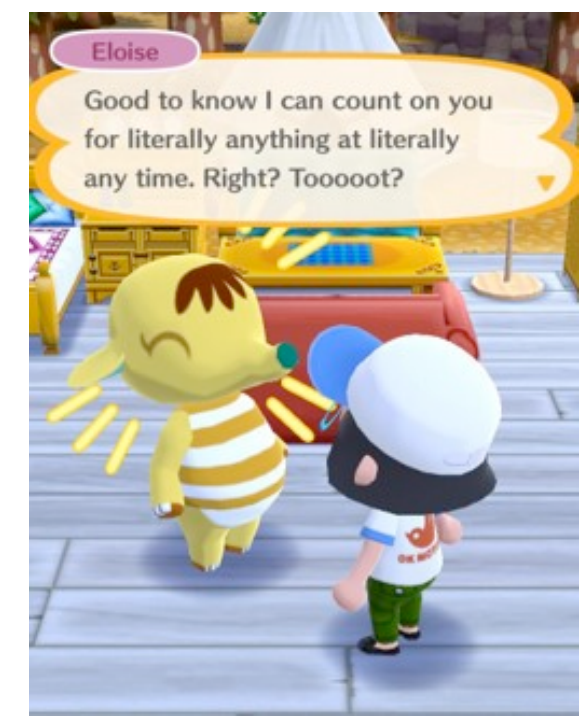

Figure 5 - I cannot help but be reminded of

Amazon CEO Jeff Bezos' infamous push for 'humans as a service'.

As the discussion concludes, however, is that really all we are left with - a mobile game that lays bare the values of capitalism? While this paper has offered a lengthy analysis of the games themselves, we ought, in closing, to question where the player stands in all of this if they do not simply accept Pocket Camp's underlying assumptions.

\section{Conclusions: Radical Slowness and the Virtual Refusal of Virtual Labour}

Throughout the preceding discussion, our aim was to outline exactly how the translation of Animal Crossing's core mechanics and values into the realm of freemium mobile games troubled the series' already charged depiction of time, leisure, and labour in a capitalist system. And while this is indeed a valuable narrative for shedding light on mobile game design or the political assumptions that are couched in videogame code, among other things, it can be rightly observed that throughout the analysis the player was a rather weak presence. This was, of course, deliberately done to better convey some of the extreme but real consequences of exporting Animal Crossing's values into a domain of financial precarity. But some closing remarks on the player are necessary.

To begin, I would like to echo my earlier comment that I do not see the player here as a cultural dupe - one is not simply a passive vessel for receiving capitalist ideology through this or any other piece of media. While certain players are more likely to be manipulated (just as some 
people are more likely to become addicted to gambling), this does not mean that all players pay money to play Pocket Camp, or any other free-to-play game. Recall Consalvo and Paul - many mobile games rely on a very small number of repeat customers - people who may spend tens of thousands of dollars on microtransactions. Some, if not most, players resist the allure of spending money to get ahead. As such, there is more to say here than that the game is simply capitalism laid bare. In fact, in my broader research I am interested in exploring how the player may be capable of using play itself to critique these coded values. While this proposition goes beyond the scope of the present text, I will conclude here with a brief discussion of what one might call, in an autonomist Marxist sense, a virtual refusal of virtual labour and what I mean by the term radical slowness. $^{15}$

My inspiration for the concept comes from work by queer poet and artist Lora Mathis (2015) in which they coined the term "radical softness" to argue for the revolutionary potential of failure, in this case the failure to hide one's emotions in a society that frames any show of feeling as weakness. In a similar vein, I argue that slowness can be a site of resistance. The society that stigmatizes any open display of 'irrational' emotions (particularly among marginalized populations such as women and people of colour) is the same one that is continually pursuing the upper limits of speed and idealizing the assault on time that is embodied in the instantaneity of drone missile strikes as much as it is in online shopping. Taking a page from Mathis, what I have come to call radical slowness is a deliberate failure to 'keep up' with the ever-accelerating rhythm of capitalist society as a political act. It is a reclamation of slowness from the financiallyenforced division between taking one's time and having one's time taken through what might be called a virtual refusal of virtual labour.

Consider, once again, some key points about Pocket Camp's gameplay. If a player is willing to wait for objects to be built, they need not spend Leaf Tickets. This in itself is not a major revelation. But in actual fact, if a player is patient enough, they need not even harvest fruit, catch fish, or befriend animals. With the resources the player is given at the start of the game along with the daily log-in bonuses one receives, a player could access most of the game without ever taking part in the game's repetitive, labour-like chores (see Figure 6). Since Pocket Camp turns natural resources and indeed friendship into currencies, the player can acknowledge this and refuse to receive that 'waged labour' in kind, and instead opt to wait for the game to give them enough materials to continue.

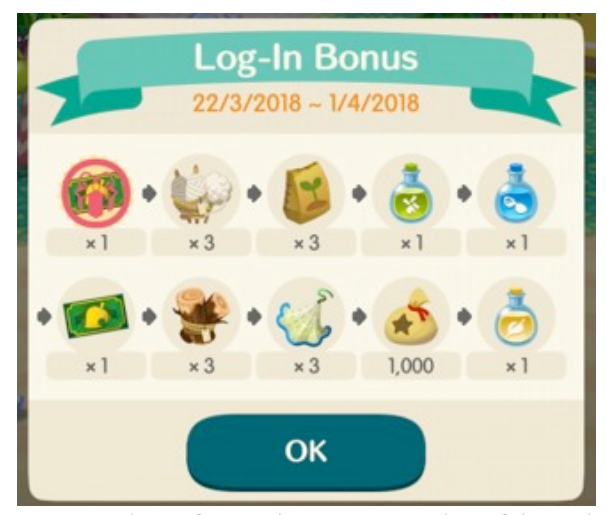

Figure 6 - An example of 10 days' worth of log-in bonuses. The game is clearly happy to reward players for their engagement, however modestly. 
Just as Mario Tronti (2007) argues that "the capitalist Class, from its birth, is in fact subordinate to the working class," I now suggest that the game is subordinate to the player and that in both cases a sort of "capitalist exploitation" emerges (p.31). While it may seem that this analogy suffers from the same problem of simulation that we identified in Bogost (it is, indeed, a virtual refusal of virtual labour), this is not a wholly negative proposition. While a refusal of labour in the context of a videogame may easily be dwarfed by any attempts to do so on the broader political-economic stage, recalling Crawford, this smaller scale may simultaneously make the success of such a refusal more attainable. Perhaps there are lessons to be drawn from playing in the forced slowness of Pocket Camp that can be applied in other spaces.

Because Pocket Camp's microtransactions and its capitalist thematic undertones blur the boundary between real and virtual currencies, a refusal of the game's labour is, in part, a refusal to engage with the game in a way that makes money. If, for instance, no one ever paid for Leaf Tickets, might the manipulative model of revenue have to be changed? By refusing to engage in the virtual labour in this simulated rural landscape, the player has the potential to articulate an autonomist critique of the game's underlying ideology through what might be called the 'radical slowness' of waiting for resources and refusing to turn one's leisure into labour. Our seat on the bench awaits.

\section{References}

Agamben, G. (2011). Nudities. Redwood City, CA: Stanford University Press.

Animal Crossing [Computer Software]. (2001). Nintendo.

Animal Crossing: New Leaf. [Computer Software]. (2012). Nintendo.

Animal Crossing: Pocket Camp. [Computer Software]. (2017). Nintendo.

Arendt, H. (1998). The human condition. Chicago, IL: University of Chicago Press. (Original work published 1958).

Barthes, R. (1967). The death of the author. Retrieved from http://www.tbook.constantvzw.org/wp-content/death_authorbarthes.pdf

Bogost, I. (September 5, 2013). Consumption and naturalism in Animal Crossing. Retrieved from http://bogost.com/writing/consumption_and_naturalism_in I.

Bogost, I. (2007). Persuasive games. Cambridge, MA: MIT Press.

Caillois, R. (1958/2001). Man, play, and games. Champaign, IL: University of Illinois Press.

Chess, S. (2017). Ready player two: Women gamers and designed identity. Minneapolis, MN: University of Minnesota Press. 
Consalvo, M. \& Paul, C. (2015). Paying to play: The evolving structure of game pricing and industry legitimacy. In Selected Papers of Internet Research 16. The 16th Annual Meeting of the Association of Internet Researchers: Phoenix, AZ.

Crawford, C. (1982). The art of computer game design. Retrieved from http://homes.lmc.gatech.edu/ bogost/courses/fall05/lcc2700/ppt/AoCGD.pdf.

Horkheimer, M. \& Adorno, T. (1944/2002). Dialectic of enlightenment. Redwood City, CA: Stanford University Press.

Humphreys, S. (2005). Productive players: Online computer games' challenge to conventional media forms. In Communication and Critical/Cultural Studies, 2(1), 37-51.

Lescop, D. \& Lescop, E. (2014). The price tag of impatience, stress and release: An exploration of the revenue model of mobile gaming companies. In SSRN Electronic Journal.

Parkins, W. \& Craig, G. (2006). Slow living. London, UK: Bloomsbury Publishing.

Schull, N. D. (2012). Addiction by design. Princeton, NJ: Princeton University Press.

Scully-Blaker, R. (2014). A practiced practice: Speedrunning through space with de Certeau and Virilio. In Game Studies, 14(1). Retrieved from http://gamestudies.org/1401/articles/scullyblaker

Scully-Blaker, R. (2018). The speedrunning museum of accidents. In Kinephanos, Special Issue. Retrieved from https://www.kinephanos.ca/2018/the-speedrunning-museum-of-accidents/

Scully-Blaker, R. (Forthcoming). Stasis and stillness: Moments of inaction in games. In Press Start, Volume and Issue TBD.

Sharma, S. (2014). In the meantime: Temporality and cultural politics. Durham, NC: Duke University Press.

Slow Food. (2015). Our philosophy. Retrieved from https://www.slowfood.com/about-us/ourphilosophy/.

Sun, Y., Zhao, Y., Jia, SH., \& Zheng, D. (2015). Understanding the antecedents of mobile game addiction: The roles of perceived visibility, perceived enjoyment and flow. Presented at Pacific Asia Conference on Information Systems. Proceedings, 141, 1-9.

Taylor, T. L. (2006). Play between worlds: Exploring online game culture. Cambridge, MA: MIT Press.

Tronti, M. (2007). Strategy of refusal. In S. Lotringer \& C. Marazzi (Eds.), Autonomia: Postpolitical politics. Edited by. Los Angeles, CA: Semiotext(e). 
Virilio, P. (2009). The aesthetics of disappearance. Los Angeles, CA: Semiotext(e).

\section{Endnotes}

${ }^{1}$ Admittedly, these moments can be somewhat circumvented by tampering with the in-game clock, a practice which, while exceedingly interesting in the context of Animal Crossing and time must be left for a different paper.

${ }^{2}$ Though there were peripherals to the game that were sold separately, these accessories only serve to expand extant gameplay opportunities and are not at all mandatory.

${ }^{3}$ Of course, in speaking of privilege and time, we would do well to keep in mind that games themselves are objects of leisure which take up time that not all may be able to 'spend'.

${ }^{4}$ This recalls Barthes' 1967 essay "Death of the Author". I take up the concept of a text's meaning laying in reader reception rather than authorial intent in a different sense at the end of this piece.

${ }^{5}$ Consider the BrainAge series, for instance, or the 'time management' genre of games which Chess analyzes as well.

${ }^{6}$ Although Consalvo and Paul are sufficient for my purposes, see also Lescop and Lescop (2014) for more on mobile games and value crafting.

${ }^{7}$ See Scully-Blaker 2014 and 2018.

${ }^{8}$ I discuss the bench in New Leaf further in a forthcoming piece for Press Start.

${ }^{9}$ A small plastic pod with a screen that simulated a virtual creature for a child to feed and care for. The product was infamously traumatizing in its use of death as a punishment for the child's oft-inevitable failure to do so.

${ }^{10}$ See Virilio (2009) - The "picnoleptic" is his term for the aesthetic of the contemporary, accelerated moment (Virilio 1). It is characterized by staccato bursts of perception rather than continuous engagement.

${ }^{11}$ See Horkheimer and Adorno (1944/2002) - The authors came under fire in their articulation of the culture industry for giving the consumer little to no agency. This figure of the dupe will be returned to in the conclusion.

12 There is something to be said here about the relatively mercenary nature of friendship in Pocket Camp when compared to earlier titles in the series!

13 Though a minor detail, in actual fact the item is built by another character who then 'instantly' ships it to the player in the vein of Amazon.

${ }^{14}$ See Sun et al (2015) or Schull (2012) - it comes as little surprise that Schull is now researching the contemporary obsession with wearable devices, mobile phone apps, and other simulacra of labour.

${ }^{15}$ The 'refusal of labour' is too complex an idea to outline here (nor indeed do all autonomists agree on an exact definition), but in this context I consider it as a rejection of the game's prescribed, labour-like way of playing in lieu of one that seeks to reclaim play as a leisurely activity. 